\title{
The effect of transplant center volume on survival after heart transplantation: A multicenter study
}

\author{
Jeffrey H. Shuhaiber, MD, ${ }^{a}$ Jeff Moore, MS, ${ }^{b}$ and David B. Dyke, MD $^{c}$
}

Objective: Few studies have examined the association between procedural volume and clinical outcomes in heart transplantation. This retrospective study was performed on a contemporary cohort of heart transplant recipients to better elucidate the effect of transplant center volume on 1-year mortality.

\begin{abstract}
Methods: Data from the Scientific Registry of Transplant Recipients were used to analyze the relationship between transplant center volume and short-term survival. Center volume designation (very low, low, medium, and high) was assigned on the basis of quartiles with approximately equal numbers of patients per group. Survival differences were explored using Cox proportional hazards modeling to adjust for differences in variables between volume groups and to determine variables associated with 1-year mortality.
\end{abstract}

Results: Between January 1, 1999, and May 31, 2005, 13,230 heart transplantations were performed at 147 transplant centers in the United States. Although most recipient and donor characteristics were similar across quartiles, larger volume centers were more likely to perform transplantations in older candidates and accept organs from older donors with longer cold ischemia times. A statistically significant relationship between transplant center volume and 1-year mortality was observed. Compared with the reference group (very low volume), the hazard ratios for the low, medium, and high-volume quartiles were $0.71,0.64$, and 0.56 , respectively $(P<.001$ for each group compared with the reference).

Conclusion: There was a significant association between transplant center volume and 1-year survival. Patients who undergo cardiac transplantation at very low-volume centers are at higher risk for early mortality than those who undergo transplantation in higher-volume centers. (J Thorac Cardiovasc Surg 2010;139:1064-9)

There is substantial evidence to suggest a strong association between center volume and outcomes, including survival, for a variety of complex surgical procedures. ${ }^{1,2}$ Centers with higher patient volume demonstrate improved early and long-term survival for cardiac surgical procedures, aortic aneurysm surgery, cancer surgery, and liver and kidney transplantation. ${ }^{2-5}$ Potential reasons for this effect include provider experience, better surgical technique and postoperative care, broader access to experienced ancillary care services, and selective referral to hospitals with better outcomes.

In the United States, more than 660,000 patients are diagnosed with heart failure every year. ${ }^{6}$ Despite impressive advances in medical and surgical therapy, cardiac transplan-

From the Department of Cardiovascular Surgery, ${ }^{\mathrm{a}}$ Harvard Medical School, Boston, Mass; Arbor Research Collaborative for Health, ${ }^{\mathrm{b}}$ and Division of Cardiovascular Medicine, ${ }^{\mathrm{c}}$ University of Michigan Health System, Ann Arbor, Mich.

Disclosures: None.

The Scientific Registry of Transplant Recipients is funded by contract number 2342005-37009C from the Health Resources and Services Administration, US Department of Health and Human Services. The views expressed herein are those of the authors and not necessarily those of the US Government.

Author responsible for data analyses: Jeff Moore, MS

Received for publication March 12, 2009; revisions received Sept 14, 2009; accepted for publication Nov 16, 2009; available ahead of print Feb 8, 2010.

Address for reprints: Jeffrey H. Shuhaiber, MD, Cincinnati Children's Hospital, 3333 Burnett Ave, MLC 2004, Cincinnati, OH 45229 (E-mail: jeffrey.shuhaiber@gmail. com).

$0022-5223 / \$ 36.00$

Copyright (c) 2010 by The American Association for Thoracic Surgery doi:10.1016/j.jtcvs.2009.11.040 tation is frequently the best option for highly selected patients with end-stage heart failure. Patients who undergo transplantation require a complex, well-organized, and technically sophisticated level of care. This level of care must extend beyond the physical domains of the transplant center to the site of the potential organ donor, thus adding to the complexity of the organ transplant process. Despite this level of sophistication, international experience in cardiac transplantation demonstrates a 1-year survival of approximately $84 \%$ and a 10 -year survival of approximately $50 \%{ }^{7}$ Mortality results from a complex interplay of donor and recipient characteristics, limitations of organ preservation, immunologic barriers, and surgical complexity. In most transplant centers, perioperative care is largely dictated by institutional protocols that are tailored to the individual donor and recipient. In addition, adequate and experienced consultative and ancillary services are necessary for successful outcomes in this highly vulnerable group of patients. This level of complexity in medical care services likely varies from center to center and may be more available in centers with larger patient volumes. ${ }^{8}$ Previous studies of cardiac transplant center volume outcomes have involved small patient numbers or limited the risk adjustment to a few variables. ${ }^{9,10}$ The primary objective of this study was to determine the effect of transplant center volume on 1-year mortality differences and identify clinical variables between heart transplant centers with different patient volumes and mortalities. 


\author{
Abbreviations and Acronyms \\ ICU = intensive care unit \\ MPSC $=$ Membership and Professional \\ Standards Committee \\ OPTN $=$ Organ Procurement and Transplantation \\ Network \\ SRTR $=$ Scientific Registry of Transplant \\ Recipients
}

plant center volume varied widely. Very low-volume centers performed between zero and 12 transplantations per year $($ median $=5)$, low-volume centers performed between 13 and 21 transplantations per year (median $=16)$, mediumvolume centers performed between 22 and 33 transplantations per year (median $=28$ ), and high-volume centers performed between 34 and 88 transplantations per year $($ median $=48)($ Table 1).

Donor characteristics varied modestly across the volume quartiles. There was a trend toward larger centers accepting a higher proportion of donor hearts from women, with the difference between very low (reference group) and high-volume quartile centers reaching statistical significance $(P<.001)$ (Table 2). High-volume centers were also more likely to accept a lower proportion of hearts from donors aged 18 to 39 years and a higher proportion of hearts from donors aged more than 50 years than very low-volume centers. In addition, there was a linear trend of longer cold ischemia times accepted by centers of higher transplant volume, with the difference among very low and low, medium, and high-volume centers all reaching statistical significance $(P<.001$, all groups).

Recipient characteristics also varied substantially among volume quartiles. There were fewer recipients of age 35 to 64 years in the high-volume quartile and more recipients of age 65 years and more in the medium and high-volume quartiles than in the very low-volume quartile $(P<.001$ for each group) (Table 3). Low and medium-volume quartile centers seemed more likely to perform transplantations in white patients than the very low-volume quartile centers. The percentage of recipients of African-American descent seemed to be relatively equal across volume quartiles. High-volume quartile centers were more likely to perform transplantations in patients with a primary diagnosis of "other" (eg, valvular, infiltrative, or congenital disease) $(P=.03)$, although the majority of patients in all volume quartiles carried the primary diagnosis of cardiomyopathy of ischemic or nonischemic origin, as expected. Medium and high-volume quartile centers performed transplantations in a smaller proportion of patients with a body mass index of $35 \mathrm{~kg} / \mathrm{m}^{2}$ or greater. Although there were statistical differences in biochemical data and hemodynamics, the magnitude of the difference was small. The percentage of chanical ventilation), creatinine, bilirubin, cardiac output, and presence or absence of a left ventricular assist device. Relative risk was evaluated using Cox proportional hazards modeling to adjust for volume quartiles and other variables associated with early (1-year) mortality. An alpha of 0.05 was considered to represent statistical significance. All analyses were conducted using SAS version 9.1 (SAS Institute Inc, Cary, NC).

\section{RESULTS}

\section{Heart Transplant Center, Donor, and Recipient Characteristics}

Between January 1, 1999, and May 31, 2005, 13,230 first-time heart transplants were performed at 147 transplant centers in the United States. During this time period, trans-

TABLE 1. Heart transplant center characteristics by volume quartile

\begin{tabular}{lrccr}
\hline & \multicolumn{4}{c}{ Volume quartile } \\
\cline { 2 - 5 } & Very low & Low & Medium & High \\
\hline No. of transplants & 3089 & 3546 & 3370 & 3225 \\
No. of centers & 84 & 35 & 19 & 9 \\
$\begin{array}{l}\text { Median annual } \\
\quad \text { volume per center }\end{array}$ & 5 & 16 & 28 & 48 \\
$\begin{array}{l}\text { Median years } \\
\quad \text { experience per center }\end{array}$ & 5.9 & 6.3 & 6.4 & 6.4 \\
\hline
\end{tabular}


TABLE 2. Heart transplant donor characteristics by volume quartile

\begin{tabular}{|c|c|c|c|c|}
\hline & \multicolumn{4}{|c|}{$\begin{array}{c}\text { Volume quartile } \\
\text { mean or } \%(P \text { value } *) \\
\end{array}$} \\
\hline & Very low & Low & Medium & High \\
\hline \multicolumn{5}{|c|}{ Donor characteristics } \\
\hline Male $(\%)$ & $72 \%$ & $70 \%(.08)$ & $70 \%(.09)$ & $67 \%(<.001)$ \\
\hline \multicolumn{5}{|l|}{ Age (y) } \\
\hline$<18$ & $13 \%$ & $13 \%(.60)$ & $12 \%(.67)$ & $11 \%(.08)$ \\
\hline $18-39$ & $59 \%$ & $57 \%(.23)$ & $58 \%(.86)$ & $55 \%(.004)$ \\
\hline $40-49$ & $20 \%$ & $20 \%(.77)$ & $20 \%(.68)$ & $21 \%(.31)$ \\
\hline$\geq 50$ & $9 \%$ & $10 \%(.08)$ & $9 \%(.83)$ & $13 \%(<.001)$ \\
\hline $\begin{array}{c}\text { Cold ischemia } \\
\text { time (min) }\end{array}$ & 173.1 & $180.7(<.001)$ & $190.1(<.001)$ & $203.3(<.001)$ \\
\hline
\end{tabular}

*Reference group is the very low transplant volume category.

patients supported with a ventricular assist device was approximately equal among the volume quartiles.

\section{Survival Analysis}

Multivariate modeling was used for determination of risk factors for 1-year posttransplant mortality. Adjusted survival analysis among the volume quartile groups demonstrated a significantly decreased 1-year risk for mortality in the low, medium, and high-volume quartile centers when compared with centers in the very low-volume quartile (Figure 1). Compared with the reference (very low-volume) group, the hazard ratios for the low, medium, and high-volume quartiles were $0.71,0.64$, and 0.56 , respectively $(P<$ .001 for each group compared with the reference group).

Additional analysis demonstrated other risk factors for survival. Donor variables associated with inferior 1-year survival included age greater than 40 years, female gender, and longer ischemia time (Table 4). Recipient variables associated with inferior 1-year survival included age 65 years or more and female gender. No difference was observed between racial groups. The primary diagnosis of nonischemic cardiomyopathy seemed to incur less risk compared with the diagnosis of ischemic cardiomyopathy, whereas the diagnosis of "other" cardiomyopathy (eg, valvular, infiltrative, and congenital diseases) incurred additional risk. The presence of hypertension, diabetes (preoperative), dialysis, or mechanical ventilation was associated with increased risk. Biochemical markers associated with increased risk included elevated levels of serum creatinine and bilirubin. Higher recipient (preoperative) cardiac output was associated with a lower risk for mortality. The presence of a left ventricular assist system was associated with a higher risk of posttransplant mortality.

\section{DISCUSSION}

The surgical and medical management of the heart transplant recipient is highly complex. Mortality within the first 90 days and 1 year after heart transplantation has been reported to be $8.3 \%$ and $12.7 \%$, respectively, indicating that
TABLE 3. Heart transplant recipient characteristics by volume quartile

\begin{tabular}{|c|c|c|c|c|}
\hline & \multicolumn{4}{|c|}{$\begin{array}{c}\text { Volume quartile } \\
\text { mean or } \%(P \text { value } *)\end{array}$} \\
\hline & $\begin{array}{l}\text { Very } \\
\text { low }\end{array}$ & Low & Medium & High \\
\hline \multicolumn{5}{|l|}{ Recipient characteristics } \\
\hline Male $(\%)$ & $76 \%$ & $75 \%(.54)$ & $77 \%(.20)$ & $77 \%(.29)$ \\
\hline \multicolumn{5}{|l|}{ Recipient age (y) } \\
\hline $18-34$ & $11 \%$ & $11 \%(.63)$ & $8 \%(<.001)$ & $10 \%(.14)$ \\
\hline $35-64$ & $81 \%$ & $81 \%(.80)$ & $79 \%(.05)$ & $75 \%(<.001)$ \\
\hline$\geq 65$ & $8 \%$ & $8 \%(.35)$ & $13 \%(<.001)$ & $15 \%(<.001)$ \\
\hline \multicolumn{5}{|l|}{ Race } \\
\hline White & $74 \%$ & $80 \%(<.001)$ & $77 \%(.001)$ & $76 \%(.09)$ \\
\hline African-American & $15 \%$ & $14 \%(.37)$ & $15 \%(.69)$ & $14 \%(.43)$ \\
\hline Hispanic & $8 \%$ & $5 \%(<.001)$ & $6 \%(<.001)$ & $7 \%(.03)$ \\
\hline Asian & $2 \%$ & $1 \%(.003)$ & $1 \%(.001)$ & $3 \%(.37)$ \\
\hline \multicolumn{5}{|l|}{ Diagnosis } \\
\hline Nonischemic & $46 \%$ & $46 \%(.87)$ & $47 \%(.38)$ & $45 \%(.40)$ \\
\hline Ischemic & $49 \%$ & $48 \%(.56)$ & $48 \%(.49)$ & $48 \%(.51)$ \\
\hline Other & $5 \%$ & $6 \%(.36)$ & $5 \%(.66)$ & $7 \%(.003)$ \\
\hline \multicolumn{5}{|c|}{ Body mass index $\left(\mathrm{kg} / \mathrm{m}^{2}\right)$} \\
\hline$<18$ & $3 \%$ & $3 \%(.19)$ & $3 \%(.20)$ & $4 \%(.43)$ \\
\hline $18-24$ & $33 \%$ & $33 \%(.85)$ & $34 \%(.37)$ & $36 \%(.01)$ \\
\hline $25-29$ & $37 \%$ & $37 \%(.99)$ & $36 \%(.31)$ & $33 \%(<.001)$ \\
\hline $30-34$ & $16 \%$ & $18 \%(.17)$ & $17 \%(.24)$ & $14 \%(.04)$ \\
\hline$\geq 35$ & $4 \%$ & $4 \%(.79)$ & $3 \%(.007)$ & $2 \%(<.001)$ \\
\hline Creatinine (mg/dL) & 1.35 & $1.36(.25)$ & $1.40(.06)$ & $1.39(<.001)$ \\
\hline Bilirubin (mg/dL) & 1.34 & $1.39(.33)$ & $1.22(.20)$ & $1.32(.15)$ \\
\hline $\begin{array}{l}\text { Hypertension, drug } \\
\text { treated }\end{array}$ & $38 \%$ & $39 \%(.32)$ & $41 \%(.03)$ & $31 \%(<.001)$ \\
\hline Diabetes, any & $17 \%$ & $19 \%(.14)$ & $19 \%(.05)$ & $17 \%(.85)$ \\
\hline $\begin{array}{l}\text { Cardiac output, } \\
\text { pretransplant }(\mathrm{L} / \mathrm{min})\end{array}$ & 4.52 & $4.61(<.001)$ & 4.58 & $4.51(<.001)$ \\
\hline $\begin{array}{l}\text { Dialysis before } \\
\text { transplant }\end{array}$ & $3 \%$ & $3 \%(.61)$ & $4 \%(<.001)$ & $2 \%(.11)$ \\
\hline Mechanical ventilation & $3 \%$ & $4 \%(.02)$ & $2 \%(.25)$ & $3 \%(.67)$ \\
\hline Ventricular assist device & $15 \%$ & $17 \%(.11)$ & $17 \%(.09)$ & $14 \%(.20)$ \\
\hline
\end{tabular}

the risk for poor outcomes is substantial. ${ }^{11}$ One of the hallmark mechanisms of quality assessment in outcomes for high-complexity procedures is analysis of case mix and case volume. ${ }^{5}$ Comparison of hospital volume effect on outcomes may reflect the ability of certain medical teams to attain superior results. This study demonstrates that donor and recipient risk-adjusted 1-year survival for heart transplantation is superior in centers that perform a higher volume of heart transplants. These results are similar to those demonstrated for transplantation of other solid organs. ${ }^{4,12}$ As an example, the risk-adjusted likelihood of 1-year allograft survival in kidney transplantation has been demonstrated to be approximately $21 \%$ superior in high-volume centers compared with very low, low, and medium-volume centers. Similarly, the risk-adjusted likelihood of 1-year patient 


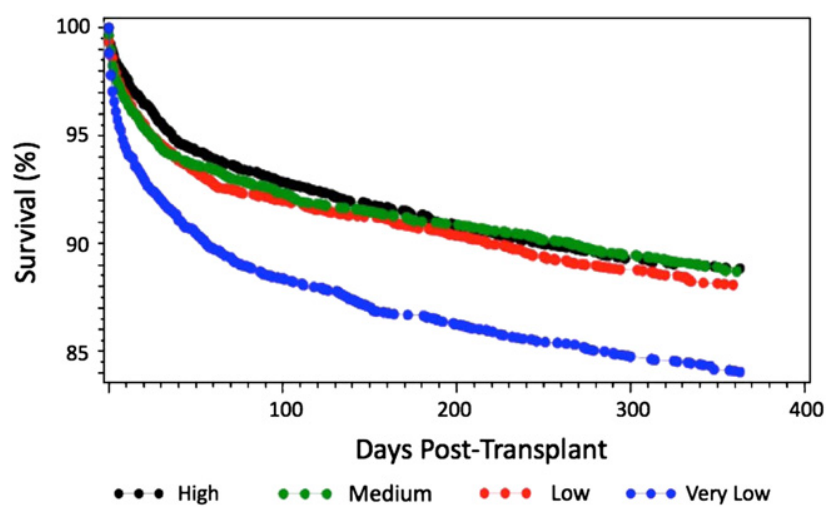

FIGURE 1. Risk-adjusted patient survival. Each curve describes survival of a hypothetic cohort of patients with average values within each volume quartile.

survival after liver transplantation has been demonstrated to be approximately $30 \%$ superior in high-volume centers compared with low-volume centers. ${ }^{4}$

Superior outcomes in heart transplantation have been demonstrated, albeit in a smaller cohort of patients and an earlier era. Hosenpud and colleagues ${ }^{10}$ demonstrated an increased risk of mortality at 1 month and 12 months $(40 \%$ and $33 \%$, respectively) in centers performing fewer than 9 cardiac transplantations per year between the years of 1987 and 1991. In addition, a recent European study that evaluated 1401 heart transplants performed over a 2-year period also demonstrated a small, yet significant, association between center volume and posttransplant mortality. ${ }^{9}$ The fact that there remains a difference in outcome based on center volume in the more contemporary cohort of heart transplant recipients evaluated in our study demonstrates that there are opportunities to improve.

Surgeon and surgical team experience are important for excellent outcomes in all fields that require technical mastery. Less obvious, but perhaps equally important, are other aspects of the care of patients posttransplantation. For example, treatment in the intensive care unit (ICU) is of paramount importance, and thus it should be anticipated that the experience of the ICU team influences outcome. It is reasonable to assume that larger-volume centers have ICU care teams that are more versatile and adept in the care of complex cases. This has been demonstrated in neonatal ICUs in California, where mortality among very low birth weight infants seemed to be lowest in high-volume ICUs. ${ }^{13}$ No less important is nursing care in the management of cardiac transplant recipients. Nursing staff who have been exposed to a larger number of transplant recipients can be expected to be more familiar with their needs, recognition of complications, and general postoperative care. ${ }^{14}$

The strategy for optimal management of heart transplant recipients is seldom straightforward. There are many aspects of their illness and posttransplant care plan that makes them vulnerable to medical complications, such as infections, renal insufficiency, and immunologic complications. There- fore, it is also reasonable to assume that consultative services with more experience in issues of transplantation (not necessarily heart) are also important for successful outcomes within a transplant program. Long-term care of heart transplant recipients is also dependent on cardiologists who specialize in heart failure and transplantation, as well as on social workers and financial consultants who have particular experience in transplantation.

Our results do not demonstrate that all very low-volume centers underperform; in fact, many smaller programs have exceptional outcomes, and we do not imply that transplantation should not occur in small-volume centers. Elimination of all low-volume centers would likely make transplantation an unobtainable option for certain patients. As an example, a low-volume center may have a lower than expected survival, but elimination of such a program might mean that patients would have to travel an unacceptable distance to be considered for transplantation. Conversely, it is reasonable to reconsider the appropriateness of allowing transplantation to occur at a low-volume center that consistently underperforms if it is within the proximity of a larger and more experienced center with better outcomes. In short, these results do not take into account the need for equal access to care based on geographic, financial, and social realities that exist for our patients and their families.

Further research as to the reasons for the discrepancy in results between centers that perform above and below expectations is a worthwhile endeavor. In a recent volumeoutcome publication based on United Network for Organ Sharing data, Weiss et $\mathrm{al}^{15}$ also found center volume to be an independent predictor of short-term mortality. The authors advocated re-evaluation of the current volume cutoff of 10 heart transplant cases recommended by Centers for Medicare and Medicaid Services. They reached this conclusion despite lack of adjustment for important variables, such as dialysis, ventricular assist device, age group stratification, and type of cardiomyopathy. Nonetheless, their analysis based on a contemporary host of transplant centers reconfirmed that a volume-outcome relationship exists but did not provide any mechanisms.

This study reconfirms these findings once again with more variable risk adjustment providing a robust conclusion that is front loaded. Most of the differences occur early on related to surgery, rejection, and infection.

There is substantial interest by payers, media, and government institutions (eg, the Department of Health and Human Services) in outcomes and quality control and improvement for complex and expensive therapies; transparency of programmatic clinical outcomes is becoming not only desirable but also mandatory. In addition, patients and families are becoming savvy at deciphering such information as it becomes more available in the current information era.

A system for maintaining quality outcomes in solid organ transplantation is currently in effect. ${ }^{16}$ The Membership and 
TABLE 4. Factors associated with recipient mortality at 1 year posttransplant

\begin{tabular}{|c|c|c|c|}
\hline Parameter & Hazard ratio & $95 \% \mathrm{CI}$ & $P$ value \\
\hline \multicolumn{4}{|l|}{ Donor characteristics } \\
\hline \multicolumn{4}{|l|}{ Age (y) } \\
\hline $0-17$ & 1.004 & $(0.85-1.18)$ & .96 \\
\hline $18-39$ & 1.000 & REF & REF \\
\hline $40-49$ & 1.24 & $(1.09-1.40)$ & .001 \\
\hline$\geq 50$ & 1.50 & $(1.29-1.75)$ & $<.001$ \\
\hline Male (vs female) & 0.88 & $(0.79-0.99)$ & .031 \\
\hline $\begin{array}{l}\text { Cold ischemia } \\
\text { time (min) }\end{array}$ & 1.003 & $(1.002-1.004)$ & $<.001$ \\
\hline \multicolumn{4}{|l|}{ Recipient characteristics } \\
\hline \multicolumn{4}{|l|}{ Age (y) } \\
\hline $18-34$ & 1.06 & $(0.89-1.27)$ & .50 \\
\hline $35-64$ & 1.00 & REF & REF \\
\hline$\geq 65$ & 1.35 & $(1.16-1.57)$ & $<.001$ \\
\hline Male (vs female) & 0.87 & $(0.77-0.99)$ & .03 \\
\hline \multicolumn{4}{|l|}{ Race } \\
\hline White & 1.00 & REF & REF \\
\hline African-American & 1.14 & $(0.99-1.32)$ & .07 \\
\hline Hispanic & 1.05 & $(0.85-1.28)$ & .67 \\
\hline Asian & 1.07 & $(0.75-1.53)$ & .72 \\
\hline Other & 1.27 & $(0.73-2.20)$ & .40 \\
\hline \multicolumn{4}{|l|}{ Diagnosis } \\
\hline Ischemic & 1.00 & REF & REF \\
\hline Nonischemic & 0.87 & $(0.77-0.97)$ & .02 \\
\hline Other & 1.32 & $(1.09-1.61)$ & .006 \\
\hline \multicolumn{4}{|l|}{ Body mass index $\left(\mathrm{kg} / \mathrm{m}^{2}\right)$} \\
\hline$<18$ & 1.33 & $(1.01-1.74)$ & .002 \\
\hline $18-24$ & 1.00 & REF & REF \\
\hline $25-29$ & 1.17 & $(1.03-1.32)$ & .02 \\
\hline $30-34$ & 1.19 & $(1.02-1.39)$ & .03 \\
\hline$\geq 35$ & 1.11 & $(0.84-1.48)$ & .47 \\
\hline Creatinine (mg/dL) & 1.12 & $(1.08-1.17)$ & $<.001$ \\
\hline Bilirubin $(\mathrm{mg} / \mathrm{dL})$ & 1.04 & $(1.03-1.04)$ & $<.001$ \\
\hline Hypertension, drug treated & 1.31 & $(1.02-1.26)$ & .02 \\
\hline Diabetes (any vs none) & 1.15 & $(1.01-1.31)$ & .03 \\
\hline Cardiac output (L/min) & 0.93 & $(0.90-0.97)$ & $<.001$ \\
\hline Dialysis before transplant & 1.74 & $(1.41-2.14)$ & $<.001$ \\
\hline Mechanical ventilation & 2.50 & $(2.07-3.01)$ & $<.001$ \\
\hline Ventricular assist device & 1.46 & $(1.29-1.66)$ & $<.001$ \\
\hline \multicolumn{4}{|l|}{ Center volume } \\
\hline Very low & 1.00 & REF & REF \\
\hline Low & 0.71 & $(0.62-0.82)$ & $<.001$ \\
\hline Medium & 0.64 & $(0.56-0.74)$ & $<.001$ \\
\hline High & 0.56 & $(0.48-0.65)$ & $<.001$ \\
\hline
\end{tabular}

Professional Standards Committee (MPSC) of the OPTN evaluates programs with low 1-year transplant grafts and survivals. Centers defined as needing review are identified, in part, by organ-specific Cox proportional hazard models that have been developed by the SRTR at the request of the MPSC. The variables used in these models are listed on the SRTR website. ${ }^{17}$ However, MPSC review of institutions is time and resource intensive. Accuracy and cost- effectiveness of the current methodology for identifying programs that underperform are currently under review by the MPSC. $^{18}$

\section{Limitations}

Our study has limitations. Most important, and as stated above, these results define association, not specific causality. Although the dataset used is robust and comprehensive, there are limitations to the quantity and quality of data collected by the OPTN, and there may have been important variables for which no adjustment was made. For example, specifics of the actual surgical procedure, such as individual surgeon experience, ${ }^{19}$ location within a teaching hospital, and contribution from trainees such as surgical residents or fellows, are not accounted for in this study. ${ }^{20}$ In addition, we did not characterize annual variation across centers given that it was not a predictor in prior studies ${ }^{9,10,15}$ and given the constraints of the data. Although the actual surgical technique used is somewhat standard, there are variations that may affect overall outcomes, such as use of a bicaval anastomosis technique, which better preserves donor cardiac anatomy, specifically the right atrium and tricuspid valve. ${ }^{21}$ Issues such as these are difficult to explore in full with a retrospective analysis of this database, although ischemia time, an important variable, and a modest surrogate for transplant complexity, was included in our analysis.

In addition to the technical aspects of cardiac transplantation mentioned above, there are other variables that were not fully explored. Nurse to patient ratio, open versus closed ICU, ${ }^{22}$ and other social and otherwise patient-specific issues that may differ significantly between low and high-volume transplant centers were not included in this analysis.

Selection bias certainly exists between low and high-volume centers, either on the part of referring physicians or the transplant center physicians themselves. Although this can, and probably does, influence our results to a degree, we believe that with inclusion of the above described donor and recipient clinical variables, the likelihood that this would nullify our findings has been minimized.

\section{CONCLUSIONS}

Higher-volume heart transplant centers use higher-risk organs in that they use older donors and donors with longer ischemia times. There is a less clear pattern of risk seen with recipient variables, although higher-volume transplant centers perform transplantations in older patients. By adjusting for donor and recipient variables, the cohort of patients receiving transplants in very low-volume centers demonstrated a $29 \%$ to $44 \%$ increased relative risk of mortality at 1 year posttransplant. Further interventions aimed at improving quality in low-volume centers (where approximately one quarter of all heart transplants are performed in the United States) are in order and may offer possibilities for quality improvement in the field of heart transplantation. 
Possible explanations for better outcomes in higher-volume centers are worth further inquiry to export their methods to lower-volume centers, specifically to the very low-volume centers.

We thank the SRTR members for support.

\section{References}

1. Kelly JV, Hellinger FJ. Physician and hospital factors associated with mortality of surgical patients. Med Care. 1986;24:785-800.

2. Birkmeyer JD, Siewers AE, Finlayson EV, et al. Hospital volume and surgical mortality in the United States. $N$ Engl J Med. 2002;346:1128-37.

3. Birkmeyer JD, Stukel TA, Siewers AE, Goodney PP, Wennberg DE, Lucas FL. Surgeon volume and operative mortality in the United States. $N$ Engl J Med. 2003;349:2117-27.

4. Axelrod DA, Guidinger MK, McCullough KP, Leichtman AB, Punch JD, Merion RM. Association of center volume with outcome after liver and kidney transplantation. Am J Transplant. 2004;4:920-7.

5. Epstein AM. Volume and outcome-it is time to move ahead. $N$ Engl J Med. 2002;346:1161-4.

6. Rosamond W, Flegal K, Furie K, et al. Heart disease and stroke statistics-2008 update. A report from the American Heart Association statistics committee and stroke statistics subcommittee. Circulation. 2008;117:e25-146.

7. Taylor DO, Edwards LB, Boucek MM, et al. Registry of the International Society for Heart and Lung Transplantation: twenty-fourth official adult heart transplant report-2007. J Heart Lung Transplant. 2007;26:769-81.

8. Urbach DR, Baxter NN. Does it matter what a hospital is "high volume" for? Specificity of hospital volume-outcome associations for surgical procedures: analysis of administrative data. BMJ. 2004;328:737-40.

9. Smits JM, De Meester J, Deng MC, et al. Mortality rates after heart transplantation: how to compare center-specific outcome data? Transplantation. 2003;75:90-6.

10. Hosenpud JD, Breen TJ, Edwards EB, Daily OP, Hunsicker LG. The effect of transplant center volume on cardiac transplant outcome. A report of the United Network for Organ Sharing Scientific Registry. JAMA. 1994;271:1844-9.

11. Annual Report of the U.S. Organ Procurement and Transplantation Network and the Scientific Registry of Transplant Recipients: Transplant Data 19972006. Health Resources and Services Administration, Healthcare Systems Bu- reau, Division of Transplantation, Rockville, MD. Heart: recipients: surviva rates. Available at: http://www.ustransplant.org/annual_reports/current/1110_ agecat_hr.htm. Accessed November 5, 2008.

12. Edwards EB, Roberts JP, McBride MA, Schulak JA, Hunsicker LG. The effect of the volume of procedures at transplantation centers on mortality after liver transplantation. N Engl J Med. 1999;341:2049-53.

13. Phibbs CS, Baker LC, Caughey AB, Danielsen B, Schmitt SK, Phibbs RH. Level and volume of neonatal intensive care and mortality in very-low-birth-weight infants. N Engl J Med. 2007;356:2165-75.

14. Aiken LH, Clarke SP, Cheung RB, Sloane DM, Silber JH. Educational levels of hospital nurses and surgical patient mortality. JAMA. 2003;290: 1617-23.

15. Weiss ES, Meguid RA, Patel ND, Russell SD, Shah AS, Baumgartner WA et al. Increased mortality at low-volume orthotopic heart transplantation centers should current standards change? Ann Thorac Surg. 2008;86: 1250-60.

16. The Organ Procurement and Transplantation Network. Policies: evaluation plan. Membership criteria and evaluation of applications. Available at: http://www. optn.org/content/policiesAndBylaws/evaluation_plan.asp. Accessed November 5, 2008.

17. Scientific Registry of Transplant Recipients. Program and OPO data: background and methodology: risk adjustment models. Available at: http://www.ustransplant org/csr/current/modtabs.aspx. Accessed November 5, 2008.

18. Wolfe RA, Arrington CJ, Kalbfleisch JD, Levine GN. A proposed new methodology for flagging transplant program for outcomes review. Am J Transplant. 2008;8(Suppl 2):266.

19. Billingsley KG, Morris AM, Dominitz JA, et al. Surgeon and hospital characteristics as predictors of major adverse outcomes following colon cancer surgery: understanding the volume-outcome relationship. Arch Surg. 2007, 142:23-31.

20. Taylor DH Jr, Whellan DJ, Sloan FA. Effects of admission to a teaching hospita on the cost and quality of care for Medicare beneficiaries. N Engl J Med. 1999; 340:293-9.

21. Schnoor M, Schäfer T, Lühmann D, Sievers HH. Bicaval versus standard technique in orthotopic heart transplantation: a systematic review and meta-analysis. J Thorac Cardiovasc Surg. 2007;134:1322-31.

22. Ghorra S, Reinert SE, Cioffi W, Buczko G, Simms HH. Analysis of the effect of conversion from open to closed surgical intensive care unit. Ann Surg. 1999;229. 163-71. 